\title{
Outcome after surgery for solid pseudopapillary pancreatic tumors in children: Report from the TREP project-Italian Rare Tumors Study Group
}

\author{
${\text { Alessandro } \text { Crocoli }^{1} \text { (D) | Chiara Grimaldi }}^{2}$ (iD $\mid$ Calogero Virgone $^{3}$ (iD) \\ Maria Debora De Pasquale ${ }^{4}$ (iD | Giovanni Cecchetto ${ }^{3}$ | Simone Cesaro ${ }^{5}$ (iD |

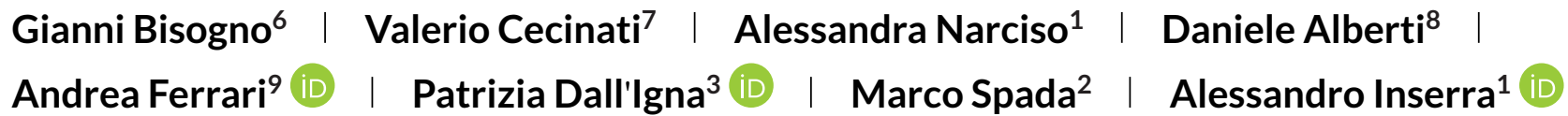

${ }^{1}$ Department of Pediatric Surgery, Bambino Gesù Children's Hospital, IRCCS, Rome, Italy

${ }^{2}$ Department of Pediatric Surgery and Transplantation, Bambino Gesù Children's Hospital, IRCCS, Rome, Italy

${ }^{3}$ Pediatric Surgery, Department of Women's and Children's Health, University of Padua, Padua, Italy

${ }^{4}$ Department of Oncohematology, Bambino Gesù Children's Hospital, IRCCS, Rome, Italy

${ }^{5}$ Pediatric Hematology-Oncology, Azienda Ospedaliera Universitaria Integrata, Verona, Italy

${ }^{6}$ Hematology Oncology Division, Department of Women's and Children's Health, University of Padova, Padova, Italy

${ }^{7}$ Pediatric Hematology and Oncology Unit, Department of Hematology, Transfusion Medicine and Biotechnology, Pescara, Italy

${ }^{8}$ Pediatric Surgery Department, ASST Spedali Civili di Brescia, Brescia, Italy

${ }^{9}$ Pediatric Oncology Unit, Fondazione IRCCS Istituto Nazionale Tumori, Milan, Italy

\section{Correspondence}

Alessandro Crocoli, Department of Pediatric Surgery, Bambino Gesù Children's Hospital, IRCCS, Piazza S. Onofrio 4, 00165 Rome, Italy. Email: alessandro.crocoli@opbg.net

A.C., C.G., and C.V. contributed equally to this article.

\begin{abstract}
Background: Solid pseudopapillary pancreatic tumors (SPPT) are an extremely rare entity in pediatric patients. Even if the role of radical surgical resection as primary treatment is well established, data about follow-up after pancreatic resection in children are scant.

Methods: A retrospective review of data from the Italian Pediatric Rare Tumor Registry (TREP) was performed. Short-term ( $<30$ days) and long-term complications of different surgical resections, as well as long-term follow-up were evaluated.

Results: From January 2000 to present, 43 patients (male:female $=8: 35$ ) were enrolled. The median age at diagnosis was 13.2 years (range, 7-18). Nine children had an incidental diagnosis, whereas 26 complained of abdominal pain and 4 of palpable mass. Tumors arose either from the head of pancreas $(n=14)$ or from body/tail $(n=29)$ : only one patient presented with metastatic disease. Resection was complete in all patients (cephalic duodenopancreatectomy vs distal resection). At follow-up (median, 8.4 years; range, 0-17 years), one recurrence occurred in a patient with intraoperative rupture. All patients are alive. Three pancreatic fistulas occurred in the body/tail group, whereas four complications occurred in the head group (one ileal ischemia, two stenosis of the pancreatic duct, and one chylous fistula).

Conclusion: Surgery is the best therapeutic option for these tumors; hence, complete resection is mandatory. Extensive resections, including cephalic duodenopancreatectomy, are safe when performed in specialized centers. Long-term follow-up should be aimed to detect tumor recurrence and to evaluate residual pancreatic function.
\end{abstract}

KEYWORDS

children, pancreas resection, pancreas, pancreatectomy, solid pseudopapillary tumor, tumor

\section{1 | INTRODUCTION}

Solid pseudopapillary tumor (SPPT) of the pancreas is a rare neoplasm that mostly affects women and adolescents. The World Health

Abbreviations: AWD, alive with disease; CDP, cephalic duodenopancreatectomy; $C R$, complete remission; $C T$, computed tomography; EFS, event-free survival; FDG-PET,

fluorodeoxyglucose-positron emission tomography; MRI, magnetic resonance imaging; OS overall survival; POD, postoperative day; SPPT, solid pseudopapillary tumor; TREP, Tumori Rari in Età Pediatrica; US, ultrasonography; WHO, World Health Organization
Organization (WHO) has recently reviewed the classification of these lesions as epithelial low-grade malignant neoplasm. ${ }^{1}$ However, malignant behavior is rare and always associated with specific histological features, such as vascular or neural invasion, peripancreatic infiltration, and nodal metastases. In this respect, complete surgical resection is the mainstay of treatment to achieve excellent long-term outcomes. $^{2-4}$ Local recurrence and metastases are rare and often reported after incomplete resection, as well as expression of intrinsic malignancy of the tumor. ${ }^{2-4}$ As a matter of fact, data on postoperative 
management and complications are scant ${ }^{4-8}$ in pediatric series: this paper focuses on surgical outcomes of pancreatic resections for SPPT, reporting the Italian experience of pancreatic resections for SPPT in pediatric patients.

\section{1 | Aim of the study}

This is a retrospective multicentric study with the aim to evaluate the incidence of short-term ( $<30$ days) and long-term ( $>30$ days) complications of pancreatic resections for SPPT in the pediatric population.

\section{2 | METHODS}

We reviewed data of patients affected by SPPT prospectively enrolled in the Italian Pediatric Rare Tumors Registry (TREP) and treated from January 2000 to present. Twelve patient in this series have been previously reported. ${ }^{9,10}$ Demographic data, clinical presentation, preoperative work-up, surgical details, pathology records, postoperative staging, and outcome were collected. All children underwent preoperative work-up, including abdominal imaging (ultrasound, computed tomography scan, and/or magnetic resonance imaging (MRI)) and blood tests.

Postoperative complications were identified and classified according to the Clavien-Dindo classification. ${ }^{11,12}$ Fisher exact test analysis was performed, and a two-tailed $P<0.05$ was considered significant.

\section{3 | RESULTS}

Forty-three patients ( 8 males and 35 females) were enrolled in the study. The median age at diagnosis was 13.2 years (range, 7-18). Median follow-up was 8.4 years ( $0-17.5$ years).

Nine patients $(21 \%)$ had an incidental diagnosis, whereas 26 patients $(60.4 \%)$ were diagnosed on abdominal ultrasound (US) performed for abdominal pain and/or vomiting; four children had a palpable mass. Details on symptoms at presentation were not recorded in four patients.

Data about preoperative blood tests were unavailable in 6 cases, while in 27 patients all data were recorded within normal ranges. Lactate dehydrogenase (LDH) was the only serum marker increased in two cases, while three patients had high CA-125 blood levels.

All patients underwent abdominal US. Sixteen children subsequently underwent abdominal computed tomography (CT), nine had abdominal MRI, and 18 had both CT and MRI. Four children received further investigations (three 99Tc-bone scan and one FDG-PET scan).

Pancreatic lesion was equal to or larger than $5 \mathrm{~cm}$ in 22 patients and less than $5 \mathrm{~cm}$ in 21 patients, ranging from 1.8 up to $14 \mathrm{~cm}$.

Tumors arose from the head of pancreas in 14 patients (32.5\%) and from body and/or tail in 29 patients (67.5\%). Eight patients underwent a diagnostic biopsy before treatment: five biopsies were performed by laparotomy or minilaparotomy, specimens were obtained in two patients through endoscopy-guided fine-needle biopsy while one patient had laparoscopic biopsy (all tumors except one were located in
TAB LE 1 Demographic and clinical features of TREP patients with SPPT

\begin{tabular}{|c|c|c|}
\hline & Number of patients & $\%$ \\
\hline \multicolumn{3}{|l|}{ Sex } \\
\hline Males & 8 & 18 \\
\hline Females & 35 & 82 \\
\hline \multicolumn{3}{|l|}{ Symptoms/presentation } \\
\hline Abdominal pain & 26 & 61 \\
\hline Incidental diagnosis & 9 & 21 \\
\hline Palpable mass & 4 & 9 \\
\hline Unknown & 4 & 9 \\
\hline \multicolumn{3}{|l|}{ Diagnostic interval } \\
\hline$<1$ month & 11 & 26 \\
\hline$>1$ month & 32 & 74 \\
\hline \multicolumn{3}{|l|}{ Tumor size } \\
\hline$<5 \mathrm{~cm}$ & 22 & 51 \\
\hline$>5 \mathrm{~cm}$ & 21 & 49 \\
\hline \multicolumn{3}{|l|}{ Tumor site } \\
\hline Head & 14 & 32 \\
\hline Body/tail & 29 & 68 \\
\hline \multicolumn{3}{|l|}{ Tumor stage } \\
\hline Localized & 41 & 95 \\
\hline Metastatic & 2 & 5 \\
\hline
\end{tabular}

the head of pancreas). All specimens but one were consistent with diagnosis of SPPT. In one case, specimens obtained by endoscopy-guided fine-needle biopsy led to diagnosis of pancreatoblastoma, while histologic examination after complete resection of the tumor revealed SPPT.

Data about demographics and clinical features are summarized in Table 1.

\section{1 | Treatment}

Twenty-seven patients out of 43 were treated by pediatric surgeons and the remaining 16 by adult surgeons. Upfront resection of the pancreatic mass was achieved in 33 cases (79\%): besides the eight patients who had a biopsy as first surgery, another patient first underwent the resection of two liver nodules (20 and $1 \mathrm{~cm}$, respectively). These lesions were misdiagnosed as a multifocal neuroendocrine tumor, but follow-up imaging later revealed a small pancreatic mass $(1.8 \mathrm{~cm})$ of the tail: a distal resection with splenectomy was therefore performed and allowed to diagnose a metastatic SPPT, 4 months after initial surgery.

Among body/tail tumors, a distal resection was performed in 21 patients (two cases laparoscopically performed), and associated splenectomy was necessary in nine cases. Four patients underwent a central pancreatectomy (one of four had a biopsy as first surgery) while three patients had a tumor enucleation (in one of three with minimally invasive technique). Among tumors arising from the head, cephalic duodenopancreatectomy (CDP) was performed in 10 patients (pylorus preservation was achieved in all of them), while in four a tumor enucleation was deemed feasible. 
One patient had a misdiagnosis of pancreatoblastoma after the initial biopsy and received four preoperative cycles of PLADO (cisplatin and doxorubicin) according to TREP guidelines: after delayed surgery, the histology on the whole mass revealed an SPPT.

One patient experienced tumor rupture (spillage) during surgery.

Pathology was evaluated according to the WHO Classification. ${ }^{13}$ Tumor was limited to pancreas in 39 cases; infiltration of peripancreatic tissue was present in two patients, and one of them also had infiltration of the splenic vein. Vascular invasion was detected in six patients and two of them had extrapancreatic disease: a regional lymph node metastasis and a liver metastasis were evident in one patient each. Perineural invasion was demonstrated in five patients and was associated with vascular invasion in three of five (one of them had a liver metastasis at diagnosis).

In two cases (one distal resection and one enucleation of a tumor of the head), the tumor seems to infiltrate resection margins and a primary reexcision was therefore performed: in both cases, no further neoplasm was found.

\section{2 | Postoperative complications}

Seven early complications were reported in six patients (13.9\%): four pancreatic fistulas (after three distal resections and one enucleation of a tumor of the head) and one chylous fistula (after CDP). All patients, but one, were treated conservatively: one high-output fistula required a CDP, both to control the fistula and to complete the resection. One postoperative bleeding after distal resection required relaparotomy on postoperative day (POD) 2 for hemostasis (the patient later developed a pancreatic fistula conservatively treated). One patient experienced a bowel ischemia due to superior mesenteric artery thrombosis successfully treated by endovascular procedure and temporary ileostomy.

Late complications include two patients with pancreatic duct stenosis after CDP both managed by surgical redo of the pancreaticojejunal anastomosis.

According to Clavien-Dindo criteria, 35 patients out of 43 had no complications. The eight patients with complications (18.6\% of the total) had the following grades: three patients had grade IIlb complications while five had grade II complications.

\section{3 | Recurrences and second tumors}

The only patient with intraoperative tumor spillage experienced a local recurrence with mesenteric lymph nodes and hepatic metastases 6 years after resection of the primary tumor, hence requiring chemotherapy ${ }^{9}$ : the patient is alive with stable disease (AWD) 11 years after recurrence. ${ }^{9}$

One child presented with single liver metastasis, 4 years after resection of the primary tumor: the liver lesion was successfully resected, and the patient obtained second complete remission (CR) and he is free from disease 3 years later. This patient had peripancreatic tissue and splenic vein invasion at diagnosis.

Additional solid lesions were recorded in two patients: one patient showed a synchronous interaortocaval paraganglioma and another patient was diagnosed with an appendicular neuroendocrine tumor (G1) 4 years after resection of pancreatic lesion.

All patients are alive: 41 in first CR, 1 in second CR, and 1 is AWD (overall survival (OS) 100\%; event-free survival (EFS) 95.3\%).

\subsection{Statistical analysis}

The Fisher exact test was performed to point out if any difference was present between the patients treated by pediatric surgeons and those treated by general surgeons in terms of outcome. Four distinct analyses were carried out: early and late complications in the two groups were evaluated in respect of all interventions, CDP-only, and CDP plus central pancreatectomy; moreover, the rate of splenectomies among distal resections in the two groups was considered. No significant difference was found (Table 2). To assess if a different rate of more complex surgery (CDP and central pancreatectomy) was present in the two group, the numbers of CDP-only and CDP plus central pancreatectomy were evaluated and showed no difference as well (Table 2).

\section{4 | DISCUSSION}

SPPT is a rare exocrine pancreatic tumor first described by Frantz in $1959^{14}$ usually affecting young women. Its indolent and slow-growing behavior is a common feature. In this respect, a surgical approach has been adapted to the slow-growing and noninvasive nature of the lesion as well as to its location in the gland.

Local recurrence, as well as metastatic disease, is often related to peripancreatic tissue infiltration, neural/vascular invasion, or lymph node spread configuring an aggressive behavior. Moreover, abdominal blunt injury could be a cause of tumor spread. ${ }^{2}$ In this respect, the impact of tumor spillage is still controversial, explaining some degree of reluctance to perform preoperative biopsies. Despite the small number of preoperative biopsies performed in this series, these procedures did not seem to influence the outcome. On the other hand, the only patient with intraoperative tumor spillage experienced a late local and metastatic relapse ( 6 years after treatment of the primary tumor). As a matter of fact, similar to adult patients, an increasing number of endoscopy-guided fine-needle biopsy has been performed in the last part of this historic cohort. The reported diagnostic yield of this technique for pancreatic tumorous lesions to date is good, with a diagnostic accuracy of $78 \%$ to $95 \%$, sensitivity $78 \%$ to $95 \%$, and specificity $75 \%$ to $100 \% .{ }^{15}$ Moreover, endoscopy-guided fine-needle biopsy proved to be a reliable tool, in spite of the lack of specific serum markers for SPPT. ${ }^{16,17}$ In this respect, review of our series did confirm absence of specific serum markers related to SPPR; slight increase of both LDH and CA-125 found in some of our patients was hence related to some degree of local inflammation as well as tumor necrosis. ${ }^{18,19}$

Surgery is the cornerstone of treatment for SPPT of pancreas, with a good prognosis expected after radical resection of the primary lesion. ${ }^{3-6,8,20-23}$ Distant metastases are present in $5 \%$ to $20 \% 24,25$ of adult cases at initial presentation, while in children the rate is lower than 5\%.4,26 However, both in adult and in pediatric patients, metastases do not seem to affect long-term prognosis once resected, 
TABLE 2 Statistical analysis

\begin{tabular}{|c|c|c|c|}
\hline Compared groups & Evaluated outcome & $P$ value & Odds ratio \\
\hline All patients (total: 43 ) & $\begin{array}{l}\text { Rate of postoperative complications } \\
\text { (total: 9) }\end{array}$ & \multirow[t]{3}{*}{$\mathrm{NS}(P=1.00)$} & 1.23 \\
\hline Pediatric surgery vs adult general surgery & $\begin{array}{l}\text { Pediatric surgery vs adult general } \\
\text { surgery }\end{array}$ & & \multirow[t]{2}{*}{$95 \% \mathrm{Cl}: 0.21-8.94$} \\
\hline 27 vs 16 & 6 vs 3 & & \\
\hline All patients (total: 43 ) & Rate of CPD performed (total: 10 ) & \multirow[t]{2}{*}{$\mathrm{NS}(P=1.00)$} & 0.86 \\
\hline 27 vs 16 & 6 vs 4 & & $95 \% \mathrm{Cl}: 0.16-5.01$ \\
\hline All patients (total: 43 ) & $\begin{array}{l}\text { Rate of CPD and central } \\
\text { pancreatectomies performed } \\
\text { (total: 14) }\end{array}$ & \multirow[t]{2}{*}{ NS $(P=0.31)$} & 0.45 \\
\hline Pediatric surgery vs adult general surgery & $\begin{array}{l}\text { Pediatric surgery vs adult general } \\
\text { surgery }\end{array}$ & & $95 \% \mathrm{Cl}: 0.10-2.04$ \\
\hline Pediatric surgery vs adult general surgery & $\begin{array}{l}\text { Pediatric surgery vs adult general } \\
\text { surgery }\end{array}$ & \multirow{2}{*}{$\mathrm{NS}(P=1.00)$} & \multirow[t]{2}{*}{$95 \% \mathrm{Cl}: 0.04-23.67$} \\
\hline 6 vs 4 & 3 vs 2 & & \\
\hline $\begin{array}{l}\text { All CPDs and central pancreatectomies } \\
\text { (total: } 14 \text { ) }\end{array}$ & Rate of complications (total: 9) & \multirow[t]{3}{*}{$\mathrm{NS}(P=1.00)$} & 0.55 \\
\hline Pediatric surgery vs adult general surgery & $\begin{array}{l}\text { Pediatric surgery vs adult general } \\
\text { surgery }\end{array}$ & & \multirow[t]{2}{*}{$95 \% \mathrm{Cl}: 0.03-7.71$} \\
\hline $7 v s 7$ & 4 vs 5 & & \\
\hline All distal pancreatectomies (total: 21 ) & Rate of splenectomies (total: 9) & \multirow[t]{2}{*}{ NS $(P=0.39)$} & 0.43 \\
\hline Pediatric surgery vs adult general surgery & $\begin{array}{l}\text { Pediatric surgery vs adult general } \\
\text { surgery }\end{array}$ & & $95 \% \mathrm{Cl}: 0.04-3.77$ \\
\hline
\end{tabular}

CDP, cephalic duodenopancreatectomy.

as confirmed in the present series (one metastatic patient out of 43). For this group of patients as well as for those with metachronous metastatic disease, the 5 -year OS rate is $>90 \% .3,4,6,20,27,28$

Laparoscopy has recently been described as a feasible approach for pancreatic lesions, including SPPT, without an increase in postoperative complications. ${ }^{29-31}$ In this series one tumor enucleation and two distal resections were laparoscopically performed: considering the epidemiology of pancreatic tumors in pediatric age and the relatively shorter expertise of pediatric surgeons in this field, this approach is recommended only in expert hands at tertiary care centers. ${ }^{31}$

Our data support the efficacy of surgical resections alone as primary treatment of SPPT. Complete resections can be achieved through different surgical procedures, varying from distal resection and enucleation to CDP and central pancreatectomy.

Nonetheless, pancreatic surgery is burdened by a high rate of early complications, late morbidity, and even mortality, as previously reported. ${ }^{5,7}$ In the literature, the rate of complications may vary from $31.8 \%$ to $62 \%,{ }^{10,29,32,33}$ and this has been related to case volume and surgeon's experience ${ }^{5}$ : even in experienced centers, ${ }^{21}$ where complications are infrequent, they happen to be severe, as in this large and multicentric series.

Pancreatic resections are commonly performed by general surgeons due to the higher incidence of pancreatic tumors in the adult population while pediatric surgeons may not be at ease with such procedures: limited series, exploring the rate of complications and the outcome in the pediatric population, are reported in the literature, and none of them probed the impact of the surgeon's experience on the outcome. The various rates of complications reported in adult and pediatric series have been investigated by Dasgupta et al, ${ }^{33}$ and the authors did not find any significant difference, attributing this lack of difference mostly to the nature of pancreatic diseases in children. Mansfield et al ${ }^{5}$ compared the outcome of pancreaticoduodenectomy between a group of children and adolescent patients versus adults and analyzed the different rate of complications but did not focus on how the surgeon's experience may have affected it.

The statistical analysis performed in this case series allowed to compare the rate of complications between patients treated by pediatric surgeon and those treated by general surgeons: different from the studies previously published, ${ }^{33}$ we had the opportunity to evaluate a homogeneous population, avoiding bias due to grouping together different pancreatic diseases, to the presence of possible comorbidities (more frequent in the adult population), and different physiology and anatomy. ${ }^{5}$

The lack of any significant difference seems to demonstrate that difficult pancreatic surgery (i.e., CDP or central pancreatectomy) for SPPT shows the same performance in the hands of pediatric surgeons. 
This may be due to the tendency to refer oncologic patients to tertiary centers: as a matter of fact, $70 \%(19 / 27)$ of the patients were operated on in three major pediatric surgical centers with large experience with oncologic and hepatobiliary diseases.

Clustering of cases may explain both the good oncological outcomes and the very low complication rates at short-term and long-term follow-up, hence recommending early referral to a tertiary care center with a multidisciplinary team (adults and pediatric surgeons, transplant surgeons) where these challenging patients can be safely managed. As recently highlighted, ${ }^{7,21}$ new perspectives on the long-term function of residual pancreas should be the focus of forthcoming clinical investigations: due to the rarity of the disease, international registries are needed to collect more data to increase knowledge on the clinical behavior of the tumor and the impact of different surgical procedures in this age group.

Interestingly, two patients (4.7\%) had an associated (synchronous or metachronous) neuroendocrine tumor: to the best of our knowledge, this is the first report of such association. Further studies are needed to better understand a possible link between these rare tumors.

\section{5 | CONCLUSIONS}

SPPT is a rare tumor in pediatric age, with the majority of cases presenting in female teenagers: a complete surgical resection remains the cornerstone of treatment. Pancreatic surgery in children is feasible and safe: experienced pediatric surgeons in high-volume centers are of paramount importance in order to achieve radical resection with low complication rate.

\section{CONFLICTS OF INTEREST}

The authors declare no conflict of interest.

\section{ORCID}

Alessandro Crocoli iD http://orcid.org/0000-0003-2157-4233

Chiara Grimaldi (iD http://orcid.org/0000-0003-3551-9286

Calogero Virgone (iD http://orcid.org/0000-0002-3651-9416

Maria Debora De Pasquale (D) http://orcid.org/0000-0003-1082-6810

Simone Cesaro (D) http://orcid.org/0000-0002-8698-9547

Andrea Ferrari (D) http://orcid.org/0000-0002-4724-0517

Patrizia Dall'Igna (iD http://orcid.org/0000-0002-3822-3272

Alessandro Inserra (iD http://orcid.org/0000-0002-5663-8674

\section{REFERENCES}

1. Basturk O, Hong SM, Wood LD, et al. A revised classification system and recommendations from the Baltimore Consensus Meeting for Neoplastic Precursor Lesions in the Pancreas. Am J Surg Pathol. 2015;39:1730-1741.

2. Irtan S, Galmiche-Rolland L, Elie C, et al. Recurrence of solid pseudopapillary neoplasms of the pancreas: results of a nationwide study of risk factors and treatment modalities. Pediatr Blood Cancer. 2016;63:1515-1521.
3. Kim MJ, Choi DW, Choi SH, Heo JS, Sung JY. Surgical treatment of solid pseudopapillary neoplasms of the pancreas and risk factors for malignancy. Br J Surg. 2014;101:1266-1271.

4. Morita K, Urushihara N, Fukumoto K, et al. Solid pseudopapillary tumor of the pancreas in children: surgical intervention strategies based on pathological findings. Pediatr Surg Int. 2014;30:253-257.

5. Mansfield SA, Mahida JB, Dillhoff M, et al. Pancreaticoduodenectomy outcomes in the pediatric, adolescent, and young adult population. J Surg Res. 2016;204:232-236.

6. Zampieri N, Schiavo N, Capelli P, Scarpa A, Bassi C, Camoglio FS. Pseudopapillary tumor in pediatric age: clinical and surgical management. Pediatr Surg Int. 2011;27:1271-1275.

7. d'Ambrosio G, del Prete L, Grimaldi C, et al. Pancreaticoduodenectomy for malignancies in children. J Pediatr Surg. 2014;49:534-538.

8. Snajdauf J, Rygl M, Petru O, et al. Duodenum-sparing technique of head resection in solid pseudopapillary tumor of the pancreas in children. Eur J Pediatr Surg. 2009;19:354-357.

9. Soloni P, Cecchetto G, Dall'igna P, Carli M, Toffolutti T, Bisogno G. Management of unresectable solid papillary cystic tumor of the pancreas. a case report and literature review. J Pediatr Surg. 2010;45:e1-6.

10. Dall'igna P, Cecchetto G, Bisogno G, et al. Pancreatic tumors in children and adolescents: the Italian TREP project experience. Pediatr Blood Cancer. 2010;54:675-680.

11. Dindo D, Demartines N, Clavien PA. Classification of surgical complications: a new proposal with evaluation in a cohort of 6336 patients and results of a survey. Ann Surg. 2004;240:205-213.

12. Clavien PA, Barkun J, de Oliveira ML, et al. The Clavien-Dindo classification of surgical complications: five-year experience. Ann Surg. 2009;250:187-196.

13. Bosman FT, Carneiro F, Hruban RH, Theise ND. WHO Classification of Tumours of the Digestive System, Vol 3. In: Bosman FT, Carneiro F, Hruban RH, Theise ND, ed. Lyon: IARC Press; 2010.

14. Frantz VK. Tumors of the pancreas atlas of tumor pathology. Atlas of Tumor Pathology.Section 7, fascicles 27 and 28. Washington, DC: Armed Forces Institute of Pathology; 1959:32-33.

15. Yamabe A, Irisawa A, Bhutani MS, et al. Efforts to improve the diagnostic accuracy of endoscopic ultrasound-guided fine-needle aspiration for pancreatic tumors. Endosc Ultrasound. 2016;5:225-232.

16. Khashab MA, Kim K, Lennon AM, et al. Should we do EUS/FNA on patients with pancreatic cysts? The incremental diagnostic yield of EUS over CT/MRI for prediction of cystic neoplasms. Pancreas. 2013;42:717-721.

17. Bal MM, Deodhar K, Shrikhande S, Shukla P, Arya S, Ramadwar M. Solid pseudopapillary tumor of the pancreas: 'experiences' and 'lessons' at a tertiary-care oncology center. Diagn Cytopathol. 2013;41:599-606.

18. Cwik G, Wallner G, Skoczylas T, Ciechanski A, Zinkiewicz K. Cancer antigens $19-9$ and 125 in the differential diagnosis of pancreatic mass lesions. Arch Surg. 2006;141:968-973; discussion 974.

19. Wang YQ, Xia WT, Wang F, Zhuang XX, Zheng FY, Lin F. Use of cancer antigen 125 , cancer antigen 19-9, and the neutrophil-to-lymphocyte ratio to diagnose mature cystic teratoma with torsion. Int J Gynaecol Obstet. 2017;137:332-337.

20. Li G, Baek NH, Yoo K, et al. Surgical outcomes for solid pseudopapillary neoplasm of the pancreas. Hepatogastroenterology. 2014;61:17801784.

21. Lindholm EB, Alkattan AK, Abramson SJ, et al. Pancreaticoduodenectomy for pediatric and adolescent pancreatic malignancy: a single-center retrospective analysis. J Pediatr Surg. 2017;52: 299-303. 
22. Muller CO, Guerin F, Goldzmidt D, et al. Pancreatic resections for solid or cystic pancreatic masses in children. J Pediatr Gastroenterol Nutr. 2012;54:369-373.

23. Sokolov YY, Stonogin SV, Donskoy DV, Povarnin OY, Vilesov AV. Laparoscopic pancreatic resections for solid pseudopapillary tumor in children. Eur J Pediatr Surg. 2009;19:399-401.

24. Papavramidis T, Papavramidis S. Solid pseudopapillary tumors of the pancreas: review of 718 patients reported in English literature. J Am Coll Surg. 2005;200:965-972.

25. Bhatnagar R, Olson MT, Fishman EK, Hruban RH, Lennon AM, Ali SZ. Solid-pseudopapillary neoplasm of the pancreas: cytomorphologic findings and literature review. Acta Cytol. 2014;58:347-355.

26. Hwang J, Kim DY, Kim SC, Namgoong JM, Hong SM. Solidpseudopapillary neoplasm of the pancreas in children: can we predict malignancy? J Pediatr Surg. 2014;49:1730-1733.

27. Campanile M, Nicolas A, LeBel S, Delarue A, Guys JM, de Lagausie P. Frantz's tumor: is mutilating surgery always justified in young patients? Surg Oncol. 2011;20:121-125.

28. Escobar MA, Bond BJ, Schopp J. Solid pseudopapillary tumour (Frantz's tumour) of the pancreas in childhood. BMJ Case Rep. 2014;2014.

29. Namgoong JM, Kim DY, Kim SC, Hwang JH, Song KB. Laparoscopic distal pancreatectomy to treat solid pseudopapillary tumors in children: transition from open to laparoscopic approaches in suitable cases. Pediatr Surg Int. 2014;30:259-266.
30. Petrosyan M, Franklin AL, Jackson HT, McGue S, Reyes CA, Kane TD. Solid pancreatic pseudopapillary tumor managed laparoscopically in adolescents: a case series and review of the literature. J Laparoendosc Adv Surg Tech A. 2014;24:440-444.

31. Cecchetto G, Riccipetitoni G, Inserra A, et al. Minimally-invasive surgery in paediatric oncology: proposal of recommendations. Pediatr Med Chir. 2010;32:197-201.

32. Leraas HJ, Kim J, Sun Z, et al. Solid pseudopapillary neoplasm of the pancreas in children and adults: a national study of 369 patients. J Pediatr Hematol Oncol. 2018;40:e233-e236.

33. Dasgupta R, Kim PC. Relationship between surgical volume and clinical outcome: should pediatric surgeons be doing pancreaticoduodenectomies? J Pediatr Surg. 2005;40:793-796.

How to cite this article: Crocoli A, Grimaldi C, Virgone C, et al. Outcome after surgery for solid pseudopapillary pancreatic tumors in children: Report from the TREP project-Italian Rare Tumors Study Group. Pediatr Blood Cancer. 2019;66:e27519. https://doi.org/10.1002/pbc.27519 